\title{
A New Dimension of Entrepreneurial Marketing and Key Challenges: A Case Study from Pakistan
}

\author{
Tayyab Amjad 1*, Shamsul Huda Binti Abdul Rani ${ }^{2}$, Shiza Binti Sa'atar ${ }^{3}$ \\ 1, 2, 3 School of Business Management, College of Business, Universiti Utara Malaysia \\ *Corresponding author: tayamja@gmail.com
}

\section{Article History \\ Received 2019-12-10 \\ Revised 2019-12-23 \\ Accepted 2019-12-31 \\ Published 2020-01-04}

\section{Keywords \\ Case Study \\ Legitimation \\ Start-up Challenges \\ Graduate Entrepreneur \\ Entrepreneurial marketing \\ Entrepreneurship Education}

How to cite?

Amjad, T., Rani, S. H. B. A., \&

Sa'atar, S. B. (2020). A New Dimension

of Entrepreneurial Marketing and Key

Challenges: A Case Study from Pakistan

SEISENSE Journal of Management,

3(1), 1-14.

doi:doi.org/10.33215/sjom.v3i1.272

\section{Abstract}

Purpose- Numerous studies have explored entrepreneurial marketing (EM) activities in the firms that are established for a few years, but the research exploring the EM activities and challenges, particularly during the start-up phase, is scant. To cover this wide gap, the current study explores in-depth the EM activities and EM challenges faced during the start-up phase by a graduate entrepreneur who has exposure to both marketing and entrepreneurship education and practical EM experiences.

Design/Methodology- In-depth case study approach has been adopted to study an SME owned and managed successfully by a graduate entrepreneur.

Findings- After rigorous data analysis, in addition to the currently known seven EM dimensions, this study has discovered a new EM dimension, i.e., 'legitimation'. Moreover, the key EM challenges in emerging economies are also identified.

Practical Implications- The results have guided future entrepreneurs regarding their investment decisions, and to the entrepreneurship education policymakers regarding pedagogical up-gradation. 


\section{Introduction}

Economic development through entrepreneurship is the key concern globally (Ha \& Hoa, 2018; Szerb \& Trumbull 2018). However, the changing marketing dynamics over the years are causing new challenges for nascent entrepreneurs, and therefore, fewer entrepreneurs are entering the markets now, and even for those, there is a greater probability to fail and exit (Agostini, 2016; Bakhtiari, 2017; Cant \& Wiid, 2017; Hanage, Scott, \& Davis 2016; Hendrickson et al., 2015; Van Scheers, 2011). The failure of nascent entrepreneurs not only affects the failing entrepreneurs but also demoralizes upcoming graduates for choosing the entrepreneurial careers (Bakhtiari, 2017). In such a challenging and risky environment, even if the graduates take the initiative to start their ventures, Hanage et al. (2016) have found such graduate entrepreneurs underprepared to perform marketing functions during the start-up phase of their small or medium-sized enterprises (SMEs).

One of the main reasons for graduate entrepreneurs being underprepared to perform marketing functions is the pedagogical gaps in the entrepreneurship education system, which leads the graduate entrepreneurs towards failure as well (Garo, 2017; Gummesson, 2014; Hutt \& Walker, 2015; Molin \& Sjöberg, 2017). Due to pedagogical gaps in entrepreneurship education system, business school graduates are found not to grasp the process of SME/entrepreneurial marketing; and lack such entrepreneurial skills to a great extent that are required to practically start an SME venture (Gosling \& Mintzberg, 2006; Mintzberg, 2009; Pfeffer \& Fong, 2004; Raelin, 2007, 2009; Rousseau, 2012; Schoemaker, 2008). In agreement with the existence of this gap, the government institutions worldwide also acknowledge that to become a successful entrepreneur, the graduating students from universities must have a wide range of SME/entrepreneurial marketing skills including product development, selling and customer acquisition (Boosting High-Impact Entrepreneurship in Australia, 2015).

Since the higher education institutions have recently recognized and acknowledged the need to develop entrepreneurship through the education system (Manimala, 2017); therefore, entrepreneurship education worldwide is still in an emerging phase. To upgrade the entrepreneurship education, there is the need to develop new curricula that are not possible without the theoretical developments, as new and advanced theories contribute towards the curricula up-gradation (Plewa et al., 2015). Similar to the general entrepreneurship education, the lack of theoretical development is highlighted by many researchers specifically in the domain of SME/entrepreneurial marketing as well (Kucel et al., 2016; Minniti, 2016; O'Cass \& Morrish, 2016; Plewa et al., 2015). The studies exploring the entrepreneurial marketing practices and challenges of entrepreneurs are rarely done by the researchers so far. This leaves a wide research gap which the current research aims to cover through the in-depth exploration of entrepreneurial marketing practices and challenges of a graduate entrepreneur who owns, manages, and successfully running his SME venture.

Entrepreneurial marketing is informal and ad hoc in nature (Franco et al., 2014), therefore, it is practiced more in the developing economies where macroeconomic indicators are unstable (Hameed et al., 2017; Singh, Saini, \& Majumdar, 2015) resulting greater challenges for entrepreneurs as compared to the developed economies. On the contrary, entrepreneurial marketing literature has an abundance of studies from developed countries, whereas the studies on developing countries are scant. Therefore, to cover this contextual gap, the current study has been conducted in a developing country, i.e., Pakistan, to get deeper insights regarding entrepreneurial marketing practices and challenges.

\section{Theoretical Background}

Morris, Schindehutte, and Laforge (2002) define entrepreneurial marketing (EM) as "the proactive identification and exploitation of opportunities for acquiring and retaining profitable customers through innovative approaches to risk management, resource leveraging and value creation." The term 'EM' is mostly used to describe the marketing undertaken by small and medium-sized firms, often at start-up or early growth phase 
(Collinson \& Shaw, 2001; Gilmore, Carson, \& Grant, 2001; Martin, 2009; Morris et al., 2002). These small and medium-sized entrepreneurial ventures most of the times have limited financial and human capitals that usually requires creative marketing tactics including heavy use of personal networks by the entrepreneurs (Ali \& Seiders, 2011; Collinson \& Shaw, 2001; Elvira, Besa, \& Elona, 2014; Gilmore et al., 2001; Martin, 2009; Morris et al., 2002).

In 2002, Morris and colleagues proposed seven dimensions of EM. These dimensions are: 1) Proactiveness, when an entrepreneur or firm behaves like an agent of change and creates a new market by offering new products or services (Lumpkin \& Dess, 2001); 2) Opportunity driven, a continuous recognition and pursuit of opportunity without regard to the resources controlled; 3) Risk management, whereby an entrepreneur stays in comfort with random variance and ambiguity; 4) Innovation focused, that promotes new and different solutions and acting of the firm as an invention factory; 5) Customer Intensity, the reinforcement of passion for the customer where an entrepreneur act as an agent for the customer; 6) Resource leveraging, doing more with limited resources; and, 7) Value creation, the ratio between the benefits and cost (Kotler, 2001).

Four of the EM dimensions, i.e., proactiveness, risk management, innovation-focused, and opportunity-driven, are derived by Morris et al. (2002) from work on entrepreneurial orientation; two dimensions, i.e., customer intensity and value creation are derived from the work on market orientation; whereas one dimension, i.e., resource leveraging is commonly found in the entrepreneurship and marketing works of literature. Since the time seven EM dimensions are proposed, they have been used as a major underpinning theory in many studies (e.g., Chaudhury et al., 2014; Krisjanous \& Carruthers, 2018; Kurgun et al., 2011; Thomas, Painbéni, \& Barton, 2013; Yang \& Gabrielsson, 2017), and other than that, there is a wide range of recent studies that have also used this theory at some point to support their research (e.g., Andersson, Evers, \& Gliga, 2018; Crick, Chaudhry, \& Crick, 2018; Crick \& Crick, 2018; Hagen, Zucchella, \& Ghauri, 2019; Matthews, Chalmers, \& Fraser, 2018). However, despite been extensively used, rare attempts could be found in the literature to extend, upgrade, or modify these dimensions. Reviewing the EM literature, it could be noticed that there are several EM practices, for instance, networking (Jones et al., 2013) that are not part of the current seven EM dimensions. Therefore, to expand the current dimensions, we aim to explore the phenomenon of EM in depth using the current EM dimensions as our interview protocol.

At higher education institutions, marketing theories are generally taught from traditional marketing textbooks (e.g., Brassington \& Pettitt, 2007; Jobber, 2009; Kotler et al., 2008), which focus on traditional marketing activities that include planning, formal marketing research and implementation of the marketing mix. Such theories are developed for large organizations that have an abundance of financial resources and marketing expertise. Owing to the constrained resources and unique characteristics of SMEs; and inherent characteristics of entrepreneurs (Gilmore et al., 2001; O’Dwyer et al., 2009), it is unsuitable to assume that SMEs can adopt the similar traditional marketing as those of large organizations (Hill, 2001). Thus, for the future SME start-ups by the graduate entrepreneurs, it is much needed to develop new marketing models that can be used to profile the EM practices of entrepreneurs in SMEs (Moriarty et al., 2008).

To solve the above-discussed issues, this study aims to explore: 1) The EM practices of the graduate entrepreneur during the startup phase of business, and 2) The EM challenges faced by the graduate entrepreneur during the start-up phase of the business. The reasons for choosing the graduate entrepreneur were to be able to discuss in-depth marketing concepts; to determine the nature of key activities and challenges, and to get recommendations based on the practical entrepreneurial experiences to upgrade the entrepreneurial education system in the higher education institutions. 


\section{Methodology}

This research aims to explore the phenomenon of EM in-depth; for that, the single case study method is the most suitable because a case study allows an in-depth understanding of the phenomenon in exploratory research (Eisenhardt, 1989; Yin, 2009). Yin (2003) defines the case study as "an empirical inquiry that investigates a contemporary phenomenon within its real-life context, especially when the boundaries between phenomenon and context are not evident." Yin (2003) also suggests that the case study approach is much useful if the contextual conditions are highly pertinent to the phenomenon of the study. Case studies usually accommodate large volumes of qualitative data obtained from a relatively smaller number of participants as compared to the quantitative studies. Therefore, at times, concerns about generalizability from case study findings are questioned due to the small sample size. However, Tsang (2014) argues that the case study has a stronger ability to make theoretical generalization than quantitative approaches. Unlike quantitative, where measures of reliability are commonly used, qualitative research calls on other approaches to ensure rigor. For instance, for the analysis of a case study, it is possible and recommended to make use of comparability and transferability criteria (Chreim et al., 2007).

A graduate entrepreneur was chosen as the key informant (Kumar et al., 1993) for this study as he has the exposure to both the entrepreneurship and marketing education; and, the EM practices during the start-up. The graduate entrepreneur belongs to the health and fitness industry and has the certification in physical training before starting his business. At the time of the interview, the studied business was one and a half years old, which makes it the most suitable for this case study as the experiences of the graduate entrepreneur were not too old to recall, hence, minimizing the recall bias. A few pre-interview meetings with the graduate entrepreneur and his staff were followed by the semi-structured interview to gather the data. Following Kurgun et al. (2011), the seven dimensions of EM given by Morris et al. (2002) were used as the interview protocol in this study. Thus, the answers for each dimension were automatically related to EM. Therefore, the interview design was guaranteed to encompass the phenomenon of EM from all theoretical perspectives.

A detailed presentation was given to the key informant explaining all the dimensions of EM beforehand. Although the business was still in the start-up phase, the informant needs to recall his experiences from the past. Therefore, considering this factor, the key informant was given ample amount of time to recall the appropriate examples of EM activities and challenges since the beginning of his venture. The graduate entrepreneur was asked the open-ended questions about EM practices and challenges during the start-up, for every single dimension of EM. Responses were audio-recorded and transcribed. Also, observations and key documents were collected, and social media pages were reviewed.

\section{Data Analysis}

Analysis of the data was first carried out manually, and later, to ensure the results, the qualitative data analysis software ATLAS.ti was used (Lewis, 2004). Interview transcripts, field notes, and all the key documents were imported into the software. The analysis started with open coding (Strauss \& Corbin, 1990), whereby each line was constantly compared within the data to find the other chunks with similar meanings. Then all the related chunks were combined using axial coding (Strauss \& Corbin, 1990), and the foregrounded themes indicated: 1) eight key dimensions as the key functions performed by the graduate entrepreneur, and 2) three themes for the EM challenges. All the findings were triangulated from internal sources to ensure the rigor, along with the analysis process (Boyatzis, 1998). These sources include employees, archival data, and social media pages. Adhering to the triangulation protocols, it has been ensured that the data gathered from the key informant must have at least one evidence from another source for its validation. The data gathered during the attempt of triangulation/validation were also uploaded in the software to complete the analysis process. 


\section{Findings and Discussion}

For the first objective, after analyzing the data, eight themes consisting of key EM functions were found. Seven of them had matched with the seven EM dimensions given by Morris et al. (2002). However, the eighth and the new theme that emerged very prominently is 'legitimation.' Thus, extending the previously known seven EM dimensions, the current study has discovered another dimension, which is also grounded in entrepreneurial and market orientations as the previous ones. Legitimation has not previously been identified in the literature as a dimension of EM. However, a study by Mort, Weerawardena, and Liesch (2012) has found it to be integral to entrepreneurial success. In the studied case, the graduate entrepreneur has demonstrated various techniques to enhance legitimacy, which is detailed in the subsequent section.

To achieve the second objective, the data analysis has suggested three EM challenges in emerging economies. This is another unique finding that has rarely been foregrounded in the entrepreneurship literature. The identified EM challenges in the current study are crucial for the investment decisions of the entrepreneurs. Following sections below detail each of the key findings:

\section{Legitimation: A New EM Dimension}

Suchman (1995) defines legitimacy as "generalized perception or assumption that the actions of an entity are desirable, proper or appropriate within some socially constructed system of norms, values, beliefs, and definitions." Over time, legitimacy has emerged as a critical but often bewildering construct in the management theory. Tornikoski and Newbert (2007) argue that there are two types of legitimacy: 1) Confirming legitimacy, and, 2) Strategic legitimacy. Confirming legitimacy is when the entrepreneurs or firms possess those characteristics that are regarded credible by the society in which they operate, whereas strategic legitimacy is when the entrepreneurs engage in such activities that are aimed to convince the external audiences that the organization is well operational. In the studied case, the graduate entrepreneur is also found to be engaged in both types of legitimation simultaneously, for instance, his fitness certification and experience in the industry, are the foremost elements that made him the most suitable person for the fitness business and therefore created confirming legitimacy. Another example is while explaining about one of the EM challenges he faced during start-up, he briefed:

\section{"Before we just started CrossFit training studio but most of the people did not know the product or have product knowledge, so we added gym as well on people's demand [...] gyms are popular and commonly found in the city whereas CrossFit training studios are very rare, and the service is not known to the general public."}

The confirming legitimacy has been strengthened by adding the gym along with the existing CrossFit training studio. That helped them not only survive but grow rapidly because it has made their business more acceptable among the targeted population. At the same time, the graduate entrepreneur has also been found to be engaged in improvising activities such as sharing live workout videos and service reviews by existing clients on the social media to enhance the strategic legitimacy of his business.

Many studies (e.g., Mort et al., 2012; Tornikoski \& Newbert, 2007; Zimmerman \& Zeitz, 2002) have found the entrepreneurs actively involved in legitimation as a part of marketing function during the start-up phases of their ventures. Tornikoski and Newbert (2007) argue that to succeed, the nascent ventures must be perceived as legitimate to the individuals and organizations with whom they aim to engage in trades. To be legitimated by the immediate public, entrepreneurs need to focus less on their new businesses' resource establishment and more on involving in behaviors that result in enhancing the perceptions of external audiences including customers, suppliers, lenders, and potential employees, that the new business is a highly capable and credible organization. 
Tornikoski and Newbert (2007) suggest that when entrepreneurs engage in improvising and resource combination behaviors, the financiers and potential customers may perceive the nascent ventures to be legitimate, and due to that, they become more prepared for exchanging resources. Entrepreneurs improvise, such as when they frequently engage in the actions or behaviors that make the new firm more palpable to others, i.e., when they promote the image of the nascent firm as a reputable business (Gartner, Bird, \& Starr, 1992). In the studied case, for instance, the graduate entrepreneur had started marketing and promotional efforts through social media even before starting the business and tried to position his brand 'well-reputed' to the audience.

Entrepreneurs exhibit resource combination behaviors, such as when they deliberately use or combine multiple types of resources they own or that are accessible, for the goods' and services' production (Tornikoski \& Newbert, 2007). For instance, in the studied case, after starting the CrossFit training studio, renting another property for the gym and purchasing/importing gym machinery were the actions directed towards the development of services, as the graduate entrepreneur states:

\section{"... when we decided to open our gym, we ordered machines and equipment from outside of our country, through abroad."}

From the EM perspective, legitimation exhibits the reliability of a firm/entrepreneur, which positively influences the trading decisions of the immediate audience. The reliability and credibility achieved through legitimation enhance the perception of the audience that they are exchanging resources with the right person/firm or from the one who has the right tools/expertise. This confirms that legitimation is different from all seven dimensions of EM by Morris et al. (2002) and has emerged as a new EM dimension in this study, as illustrated in Figure 1.

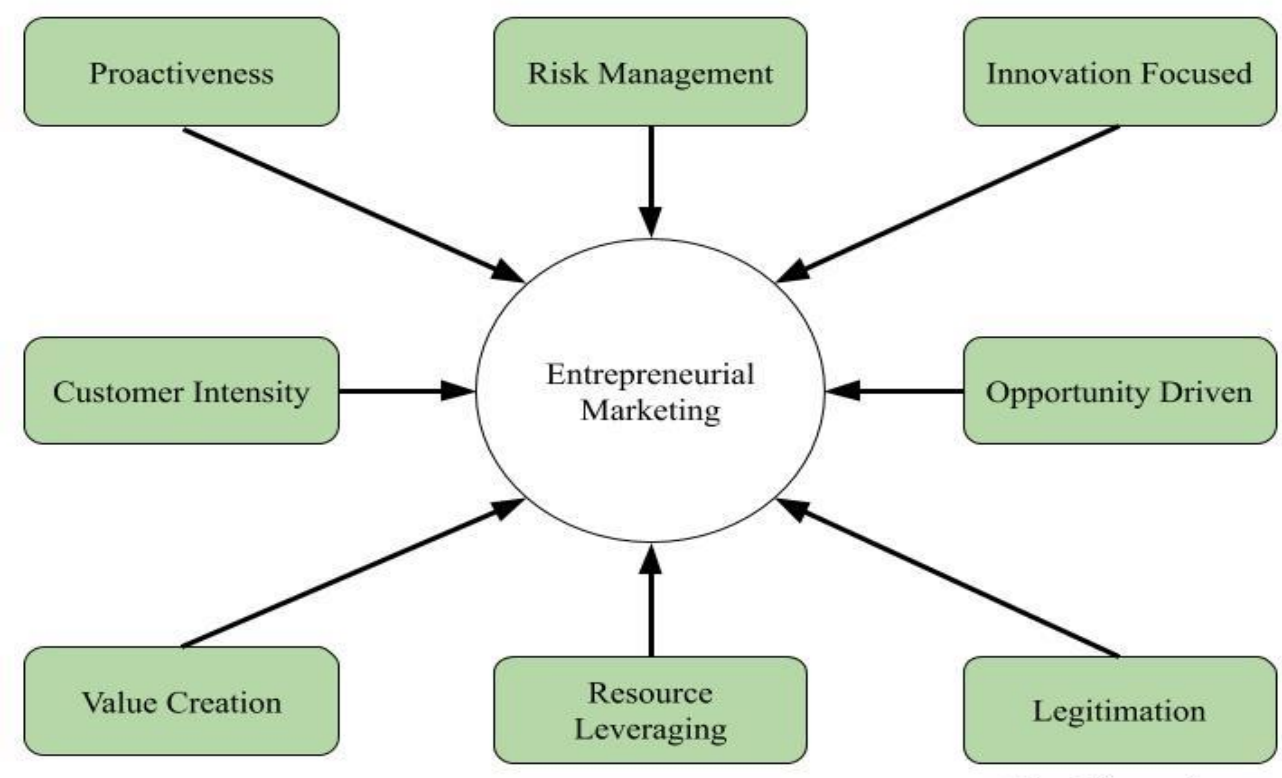

New Dimension

Figure 1 - Extension of the existing EM dimensions

EM has been studied in the light of different theoretical viewpoints, among those, seven dimensions of EM by Morris et al. (2002) has been one of the most frequently used theories. These dimensions are proactiveness, risk 
management, innovation, customer intensity, resource leveraging, opportunity-driven, and value creation. These dimensions have been used as underpinning theory in many studies (e.g., Chaudhury et al., 2014; Krisjanous \& Carruthers, 2018; Kurgun et al., 2011; Thomas et al., 2013; Yang \& Gabrielsson, 2017) and other than that, there is a wide range of recent studies that have also used this theory at some point to support their research (e.g., Andersson et al., 2018; Crick et al., 2018; Crick \& Crick, 2018; Hagen et al., 2019; Matthews et al., 2018). The current study has also used the dimensions of EM as the interview protocol to explore the practices of a graduate entrepreneur during the start-up phase. While doing so, a new EM dimension, i.e., 'legitimation,' has been discovered by this study (see Figure 1).

In the developing economies, the techniques used for legitimation by the entrepreneurs are somewhat different than in developed economies. For instance, a study was done by Mort et al. (2012) in the US has reported the entrepreneurs using a particular (American) website style to enhance the legitimacy of their business, results improve their online sales. Whereas in developing countries like Pakistan, due to the lack of cyber laws (Awan et al., 2016; Khan et al., 2013), people are much more reluctant in online purchases. Hence, specific technical features of products/services such as website style or payment security do not create legitimacy. Rather personal forms of legitimation are widely used; for example, personal experience, certifications, and qualifications are more frequently used by the entrepreneurs for legitimation.

Another study by Alonso (2012) has highlighted the winemakers in a developed economy using the 'buy local' slogan to promote their products and using their heritage to create legitimacy. On the other hand, in developing economies, due to the lack of high-quality manufacturing, consumers generally prefer to buy/use imported products (Papadopoulos, Heslop, \& Bamossy, 1990). It is also evident in the case studied, that despite the presence of local manufacturers, the graduate entrepreneur has imported complete gym machinery at a higher cost than local because the 'imported machinery' is regarded as credible and thus creates confirming legitimacy.

Although many studies in the past have identified entrepreneurs engaged in legitimation (e.g., Mort et al., 2012; Thompson, Purdy, \& Ventresca, 2018; Wang, Thornhill, \& De Castro, 2017), however, no study to date in the entrepreneurship literature has recognized legitimation as a core EM dimension. Legitimacy as a domain has certainly received less attention from the entrepreneurship researchers as compared to the level of involvement in legitimation by the entrepreneurs. The future entrepreneurs need to consider legitimation along before starting their new ventures because to gain confirming legitimacy whereby future entrepreneurs may need to gain experience and expertise; it could require several months or years.

\section{Entrepreneurial Marketing Challenges in Emerging Economies}

The second objective of the current study was to explore the EM challenges faced by the graduate entrepreneur during the start-up phase. Thus, along with the identification of a new EM dimension, the current case study has also brought forward the EM challenges in the emerging economies. While analyzing the data for EM challenges, three major themes were highlighted as detailed below:

\section{Change Resistant Culture}

Like many underdeveloped countries, Pakistan is also comprised of change resistance culture, and generally, people in Pakistan are reluctant to adopt the innovation (Haleem, 2015). Hofstede (2019) has also indicated this in the 6-D model that the people in the underdeveloped country like Pakistan mostly follow the philosophy of collectivism and represent a highly restrained society. In the studied case, the graduate entrepreneur has also encountered the change-resistant behavior in his targeted audience. He offered the new services of CrossFit training and high-intensity interval training (HIIT) that were not offered elsewhere in the town. Despite intensively promoting the services for several months, he could not convince the targeted audience on the benefits of the new facilities; thus he was compelled to open a traditional gym as well to gain legitimacy among the targeted audience, as he states: 
"... we just operated CrossFit training studio, but most of the people did not know the product or have product knowledge, so we added the gym as well on people's demand. [...] after eight to nine months."

Underdeveloped economies worldwide are usually changing resistant, which is perhaps one of the reasons for their slow development. This resistance to change shows in people's behaviors, actions, decision-making, and choices, and this reality could not be changed in a short period (Haleem, 2015). Entrepreneurs in the emerging economies need to understand consumers' change-resistant mindset, and it might require massive spending on marketing communications, particularly if an entrepreneur wants to bring innovation to the market. Future entrepreneurs must consider this reality while making their investment decisions in any emerging economy.

\section{Weak Legislation and Law Enforcement}

The weak legislation and implementation of laws in underdeveloped countries create big challenges for businesses, particularly during the start-up phase. For instance, in Pakistan, among other major problems, one is the electricity cost for commercial consumers is very high; moreover, due to the electricity production shortage, the businesses face eight to ten hours of electricity shut down every day. Due to these issues, many businesses have to make the extra investment to buy and install solar panels to produce their electricity. This helps in lowering the long-term electricity cost as well as avoiding the electricity shutdowns (Sheilds, 2009). After trying to follow the same trend, the graduate entrepreneur faced a loss, and he states that:

"... initially, we decided to install solar panels for lowering the operating cost of our business, but we faced few problems in this, [...] so one of them was that our building was on rent and the owner did not allow us after we purchased the equipment, so he refused to let us install the equipment on this building and in this shape, we faced huge loss. [...] Yes, we communicated with him earlier, but at that time, he was agreed, but after when we purchased the solar panels, then he refused that to be fitted."

The actual challenge faced by the graduate entrepreneur was when he could not take any legal action against the miscommunication that occurred between him and his landlord. So eventually, the graduate entrepreneur had to take the loss only because his investment was on the line. In developing economies, due to weak legislation and law enforcement, it is usual for entrepreneurs to face high monetary risks, as in case of any dispute, they are often unable to get the justice easily. This reality must be considered by future entrepreneurs while making their investment decisions in emerging economies.

\section{Lack of Professionalism}

Another major problem in underdeveloped countries like Pakistan is the lack of professionalism (Rizvi \& Elliott, 2007). For instance, in the studied case, a similar problem has been encountered continuously by the graduate entrepreneur from the first day of his business, as a frequent observation detailed below:

"People's behavior and businesses in Punjab province generally lack professionalism. Due to this, entrepreneurs, marketers, and customer serving staff prefer to make emotional business relations rather than dealing professionally. So, this type of emotional relationship in business is sometimes very hard to manage."

This unprofessionalism in business communication has created a major challenge for the graduate entrepreneur in training the new staff and delivering professional services, as he mentions:

"Our biggest challenge was staff because we had to train them for this type of service. [...] I think we didn't know how to train our staff. [...] it took a long time to train them." 
According to Askary (2006), lack of professionalism is a common problem in the developing countries, particularly in the Middle Eastern and Southeast Asian Islamic states. He (2006) has also proved that the countries ranking higher on individualism in the Hofstede's (2019) 6-D model, are proved to be higher in professionalism, and the countries lower in rankings of 'uncertainty avoidance' and 'power distance' are also more likely to be ranked high in professionalism. In the case of Pakistan, it ranks contrastingly, i.e., it ranks low on 'individualism' and high in 'uncertainty avoidance' and 'power distance,' thus proved to be a society with a lack of professionalism. Lack of professionalism is a major problem in developing countries, which requires the extra investment or, in some cases running costs for the business; for instance, entrepreneurs may need to invest heavy resources in the training of employees (Rizvi \& Elliott, 2007). These issues must be considered and deeply analyzed by the entrepreneurs well before entering into the markets of emerging economies. These realities of emerging economies could not be changed in a short period; however, improving the literacy rate by providing high-quality education could probably change this reality in the long-term.

\section{Conclusion}

This case study has aimed to explore in-depth the EM activities and EM challenges faced by the graduate entrepreneur who has exposure to both entrepreneurship and marketing education; and practical EM experiences. The reasons for choosing such graduate entrepreneurs as the key informant were to be able to discuss in-depth marketing concepts, to determine the nature of key activities and challenges, and to get recommendations based on the practical entrepreneurial experiences. The currently known seven dimensions of EM were used as the interview protocol in this study in an attempt to extend or modify the existing dimensions. After rigorous analysis, this study has first discovered a new EM dimension, i.e., 'legitimation,' in addition to the currently known seven EM dimensions. Future entrepreneurs need to consider legitimation along before starting their new ventures as it may take months or years to gain legitimacy. Secondly, a range of EM challenges in emerging economies have been found that are hard and costly to control, and the entrepreneurs must consider and analyze these while making their investment decisions in emerging economies. The graduate entrepreneurs, in particular, could be able to overcome these challenges if they are trained accordingly at the higher education institutions. If the higher education institutions follow the recommendations given in this study, it could assist them in producing high-quality graduate entrepreneurs in the future that would be able to survive and contribute to the development of the economy.

\section{Recommendations}

The identification of legitimation as an EM dimension opens the avenues for future researchers to further explore the ways entrepreneurs engage in legitimation and how that varies from one industry/sector to another. The researchers could also further explore the typologies of legitimation and develop quantitative scales to determine the minimum acceptable level of each type of legitimation for the businesses to succeed. Further, the future researchers could also explore the impact of all identified EM challenges on each, entrepreneurial failure and investment decisions of entrepreneurs.

The pedagogical gap in the entrepreneurship education system can be seen from the examples of many developing countries, for instance, in Pakistan, after reviewing the higher education institutions' entrepreneurship education systems, it has been found that the specialized entrepreneurship programs are rarely offered to the students. The options that are widely available to the students are the programs of traditional business administration, designed and focused on getting employment in large organizations. This leaves the new graduate entrepreneurs untrained in many key entrepreneurial skills like EM. In few higher education institutions where entrepreneurship education is available, upon reviewing the pedagogical structure, it has been noticed that entrepreneurship education is delivered in the same way as the traditional business/marketing education (i.e., through coursework). Whereas, in line with the graduate entrepreneur's recommendation, 
Piperopoulos and Dimov (2015) also suggest that entrepreneurship courses should be designed and delivered with the 'practically oriented' context and teaching pedagogies because practically oriented programs develop significant entrepreneurial skills that affect highly on the practical outcomes among graduate entrepreneurs. Hence, there is a high need to develop EM pedagogies by business schools based on practical learning, particularly in emerging economies, to substantially fill this pedagogical gap in entrepreneurship education.

Ahmad and Buchanan (2015) also argue that rather than solely focusing on functional understanding of entrepreneurship or business (like traditional business coursework), the objectives of strengthening entrepreneurship education in universities should be reconsidered in such a way as to enhance graduates' acquisition of skills and competencies needed to initiate and retain new businesses. Thus, higher education institutions need to upgrade entrepreneurship education by developing new EM pedagogies focusing on practical learning and skill development, so that in future, high-quality graduate entrepreneurs could be produced that are better prepared to encounter EM challenges to survive and contribute to the development of the economy.

Funding: This research received no external funding.

Acknowledgments: We acknowledge the valuable contribution and support of Mr. Zohaib Bukhari, the graduate entrepreneur; and owner and manager of the studied firm.

Conflicts of Interest: The authors declare no conflict of interest.

\section{References}

Agostini, L. (2016). Organizational and managerial activities in the development process of successful SME marketing networks. European Management Review, 13(2), 91-106.

Ahmad, S. Z., \& Buchanan, R. F. (2015). Entrepreneurship education in Malaysian universities. Tertiary Education and Management, 21(4), 349-366.

Ali, A., \& Seiders, K. (2011). Entrepreneurial marketing. In The portable MBA in entrepreneurship (4th ed., Vol. 28, pp. 83-108). Hoboken, NJ, USA: John Wiley \& Sons, Inc.

Alonso, A. D. (2012). Promotional efforts of muscadine wines and muscadine-related products: The case of southern United States wineries. International Journal of Consumer Studies, 36(6), 702-709.

Andersson, S., Evers, N., \& Gliga, G. (2018). Entrepreneurial marketing and born global internationalisation in China. Qualitative Market Research: An International Journal, 21(2), 202-231.

Askary, S. (2006). Accounting professionalism - A cultural perspective of developing countries. Managerial Auditing Journal, 21(1), 102-111.

Awan, J. H., Memon, S., Shah, M. H., \& Awan, F. H. (2016). Security of e-government services and challenges in Pakistan. In 2016 SAI Computing Conference (SAI) (Vol. 103, pp. 1082-1085). IEEE.

Bakhtiari, S. (2017). Entrepreneurship dynamics in Australia: Lessons from micro-data. Retrieved from https://industry.gov.au/Office-of-the-Chief-Economist/Research-Papers/Documents/2017-ResearchPaper-5-Entrepreneurship-Dynamics-in-Australia.pdf

Blankson, C., Motwani, J. G., \& Levenburg, N. M. (2006). Understanding the patterns of market orientation among small businesses. Marketing Intelligence \& Planning, 24(6), 572-590.

Boosting high-impact entrepreneurship in Australia. (2015).

Boyatzis, R. E. (1998). Transforming qualitative information: Thematic analysis and code development. Sage.

Brassington, F., \& Pettitt, S. (2007). Principles of marketing (4th ed.). Harlow: FT/Prentice-Hall.

Cant, M., \& Wiid, J. (2017). The use of traditional marketing tools by SMEs in an emerging economy: A South African perspective. Problems and Perspectives in Management, 14(1), 64-70. 
Carson, D., Gilmore, A., Cummins, D., O’Donnell, A., \& Grant, K. (1998). Price setting in SMEs: Some empirical findings. Journal of Product \& Brand Management, 7(1), 74-86.

Cavusgil, S. T., \& Cavusgil, E. (2012). Reflections on international marketing: Destructive regeneration and multinational firms. Journal of the Academy of Marketing Science, 40(2), 202-217.

Chaudhury, S. R., Albinsson, P. A., Shows, G. D., \& Moench, V. (2014). The winemaker as entrepreneurial marketer: An exploratory study. International Journal of Wine Business Research, 26(4), 259-278.

Chreim, S., Williams, B. E. B., \& Hinings, C. R. B. (2007). Interlevel influences on the reconstruction of professional role identity. Academy of Management, 50(6), 1515-1539.

Collinson, E., \& Shaw, E. (2001). Entrepreneurial marketing: A historical perspective on development and practice. Management Decision, 39(2), 761-767.

Crick, D., Chaudhry, S., \& Crick, J. M. (2018). Risks/rewards and an evolving business model: A case study of a small lifestyle business in the UK tourism sector. Qualitative Market Research: An International Journal, 21(2), 143-165.

Crick, J. M., \& Crick, D. (2018). Angel investors' predictive and control funding criteria. Journal of Research in Marketing and Entrepreneurship, 20(1), 34-56.

Day, J., Dean, A. A., \& Reynolds, P. L. (1998). Relationship marketing: Its key role in entrepreneurship. Long Range Planning, 31(6), 828-837.

Eisenhardt, K. M. (1989). Building theories from case study research. Academy of Management Review, 14(4), 532550.

Elvira, F., Besa, X., \& Elona, F. (2014). The spontaneity of international market and the need for entrepreneurial marketing: Evidence of Albanian entrepreneurs in Italy. Business Management Dynamics, 3(10), 14-20.

Franco, M., de Fátima Santos, M., Ramalho, I., \& Nunes, C. (2014). An exploratory study of entrepreneurial marketing in SMEs. Journal of Small Business and Enterprise Development, 21(2), 265-283.

Garo, E. (2017). Gap between theory and practice in management education. In Case studies as a teaching tool in management Education (pp. 264-277). IGI Global.

Gartner, W. B., Bird, B. J., \& Starr, J. A. (1992). Acting as If: Differentiating entrepreneurial from organizational behavior. Entrepreneurship Theory and Practice, 16(3), 13-32.

Gilmore, A., Carson, D., \& Grant, K. (2001). SME marketing in practice. Marketing Intelligence \& Planning, 19(1), 6-11.

Gosling, J., \& Mintzberg, H. (2006). Management education as if both matter. Management Learning, 37(4), 419_ 428.

Gummesson, E. (2014). The theory/practice gap in B2B marketing: Reflections and search for solutions. Journal of Business \& Industrial Marketing, 29(7/8), 619-625.

Ha, N. T. T., \& Hoa, L. B. (2018). Evaluating entrepreneurship performance in Vietnam through the global entrepreneurship development index approach. Journal of Developmental Entrepreneurship, 23(1), 1-19.

Hagen, B., Zucchella, A., \& Ghauri, P. N. (2019). From fragile to agile: Marketing as a key driver of entrepreneurial internationalization. International Marketing Review, 36(2), 260-288.

Haleem, F. (2015). Planning change in an organization; MCB bank limited, Pakistan. Journal of Central Banking Theory and Practice, 4(2), 75-107.

Hameed, W. U., Azeem, M., Ali, M., Nadeem, S., \& Amjad, T. (2017). The role of distribution channels and educational level towards insurance awareness among the general public. Int. J Sup. Chain. Mgt Vol, 6(4), 308.

Hanage, R., Scott, J. M., \& Davies, M. A. P. (2016). From “great expectations" to "hard times." International Journal of Entrepreneurial Behavior \& Research, 22(1), 17-38.

Hendrickson, L., Bucifal, S., Balaguer, A., \& Hansell, D. (2015). The employment dynamics of Australian entrepreneurship. 
Hill, J. (2001). A multidimensional study of the key determinants of effective SME marketing activity: Part 1. International Journal of Entrepreneurial Behavior \& Research, 7(5), 171-204.

Hofstede, G. (2019). The 6 dimensions of national culture. Retrieved January 5, 2019, from https://www.hofstede-insights.com/models/national-culture/

Hutt, M. D., \& Walker, B. A. (2015). Bridging the theory-practice gap in business marketing: Lessons from the field-the JBBM at 21. Journal of Business-to-Business Marketing, 22(1-2), 67-72.

Jobber, D. (2009). Principles and practice of marketing (6th ed.). London: McGraw-Hill Companies.

Jones, R., Suoranta, M., \& Rowley, J. (2013). Strategic network marketing in technology SMEs. Journal of Marketing Management, 29(5-6), 671-697.

Khan, W. A., Yousaf, S., Mian, N. A., \& Nawaz, Z. (2013). E-commerce in Pakistan: Growth potentials and epayment solutions. In 2013 11th International Conference on Frontiers of Information Technology (pp. 247-252). IEEE.

Kotler, P., Wong, V., Saunders, J., \& Armstrong, G. (2008). Principles of marketing (5th ed.). Harlow: FT/PrenticeHall.

Kotler, P. (2001). Marketing management (Millenium). Prentice Hall Inc.

Krake, F. G. B. J. M. (2005). Successful brand management in SMEs: A new theory and practical hints. Journal of Product and Brand Management, 14(4), 228-238.

Krisjanous, J., \& Carruthers, J. (2018). Walking on the light side. Qualitative Market Research: An International Journal, 21(2), 232-252.

Kucel, A., Róbert, P., Buil, M., \& Masferrer, N. (2016). Entrepreneurial Skills and Education-Job Matching of Higher Education Graduates. European Journal of Education, 51(1), 73-89.

Kumar, N., Stern, L. W., \& Anderson, J. C. (1993). Conducting interorganizational research using key informants. Academy of Management, 36(6), 1633-1651.

Kurgun, H., Bagiran, D., Ozeren, E., \& Maral, B. (2011). Entrepreneurial marketing-the interface between marketing and entrepreneurship: A qualitative research on boutique hotels. European Journal of Social Sciences, 26(3), 340-357.

Lewis, R. B. (2004). NVivo 2.0 and ATLAS.ti 5.0: A comparative review of two popular qualitative data-analysis programs. Field Methods, 16(4), 439-464.

Lumpkin, G. T., \& Dess, G. G. (2001). Linking two dimensions of entrepreneurial orientation to firm performance: The moderating role of environment and industry life cycle. Journal of Business Venturing, 16(5), 429-451.

Manimala, M. J. (2017). Promoting Entrepreneurship: The Role of Educators. In Entrepreneurship Education (pp. 393-407). Springer, Singapore.

Martin, D. M. (2009). The entrepreneurial marketing mix. Qualitative Market Research: An International Journal, 12(4), 391-403.

Matthews, R. S., Chalmers, D. M., \& Fraser, S. S. (2018). The intersection of entrepreneurship and selling: An interdisciplinary review, framework, and future research agenda. Journal of Business Venturing, 33(6), 691719.

Minniti, M. (2016). The foundational contribution to entrepreneurship research of William J. Baumol. Strategic Entrepreneurship Journal, 10(2), 214-228.

Mintzberg, H. (2009). Managers not MBAs: A hard look at the soft practice of managing and management development. Berrett-Koehler.

Molin, S., \& Sjöberg, A. (2017). Addressing the gap between theory and practice: A marketing-as-practice approach. Lund.

Moriarty, J., Jones, R., Rowley, J., \& Kupiec-Teahan, B. (2008). Marketing in small hotels: a qualitative study. Marketing Intelligence \& Planning, 26(3), 293-315. 
Morris, M. H., Schindehutte, M., \& LaForge, R. W. (2002). Entrepreneurial marketing: A construct for integrating emerging entrepreneurship and marketing perspectives. Journal of Marketing Theory and Practice, 10(4), 1-19.

Mort, G. S., Weerawardena, J., \& Liesch, P. (2012). Advancing entrepreneurial marketing: Evidence from born global firms. European Journal of Marketing, 46(3/4), 542-561.

O'Cass, A., \& Morrish, S. (2016). Anatomy of entrepreneurial marketing. Journal of Strategic Marketing, 24(1), 24.

O’Dwyer, M., Gilmore, A., \& Carson, D. (2009). Innovative marketing in SMEs. European Journal of Marketing, 43(1/2), 46-61.

Papadopoulos, N., Heslop, L. A., \& Bamossy, G. (1990). A comparative image analysis of domestic versus imported products. International Journal of Research in Marketing, 7(4), 283-294.

Pfeffer, J., \& Fong, C. T. (2004). The business school "business": Some lessons from the US experience. Journal of Management Studies, 41(8), 1501-1520.

Piperopoulos, P., \& Dimov, D. (2015). Burst bubbles or build steam? Entrepreneurship education, entrepreneurial self-efficacy, and entrepreneurial intentions. Journal of Small Business Management, 53(4), 970-985.

Plewa, C., Galán-Muros, V., \& Davey, T. (2015). Engaging business in curriculum design and delivery: a higher education institution perspective. Higher Education, 70(1), 35-53.

Raelin, J. A. (2007). Toward an epistemology of practice. Academy of Management Learning \& Education, 6(4), 495519.

Raelin, J. A. (2009). The practice turn-away: Forty years of spoon-feeding in management education. Management Learning, 40(4), 401-410.

Rizvi, M., \& Elliott, B. (2007). Enhancing and sustaining teacher professionalism in Pakistan. Teachers and Teaching: Theory and Practice, 13(1), 5-19.

Rousseau, D. M. (2012). Designing a better business school: Channelling Herbert Simon, addressing the critics, and developing actionable knowledge for professionalizing managers. Journal of Management Studies, 49(3), $600-618$.

Schoemaker, P. J. H. (2008). The future challenges of business: Rethinking management education. California Management Review, 50(3), 119-139.

Sheilds, P. (2009). Solar power saves $\$ 500 \mathrm{k}$ in annual energy costs. Journal / American Water Works Association, 101(7), 30-33.

Simpson, M., \& Taylor, N. (2002). The role and relevance of marketing in SMEs: Towards a new model. Journal of Small Business and Enterprise Development, 9(4), 370-382.

Singh, A., Saini, G. K., \& Majumdar, S. (2015). Application of social marketing in social entrepreneurship: Evidence from India. Social Marketing Quarterly, 21(3), 152-172.

Strauss, A., \& Corbin, J. M. (1990). Basics of qualitative research: Grounded theory procedures and techniques. Sage Publications.

Suchman, M. C. (1995). Managing legitimacy: Strategic and institutional approaches. Academy of Management, 20(3), 571-610.

Szerb, L., \& Trumbull, W. N. (2018). Entrepreneurship development in Russia: Is Russia a normal country? An empirical analysis. Journal of Small Business and Enterprise Development, 25(6), 902-929.

Thomas, L. C., Painbéni, S., \& Barton, H. (2013). Entrepreneurial marketing within the French wine industry. International Journal of Entrepreneurial Behavior \& Research, 19(2), 238-260.

Thompson, T. A., Purdy, J. M., \& Ventresca, M. J. (2018). How entrepreneurial ecosystems take form: Evidence from social impact initiatives in Seattle. Strategic Entrepreneurship Journal, 12(1), 96-116.

Tornikoski, E. T., \& Newbert, S. L. (2007). Exploring the determinants of organizational emergence: A legitimacy perspective. Journal of Business Venturing, 22(2), 311-335. 
Tsang, E. W. K. (2014). Generalizing from research findings: The merits of case studies. International Journal of Management Reviews, 16(4), 369-383.

Van Scheers, L. (2011). SMEs' marketing skills challenges in South Africa. African Journal of Business Management, 5(13), 5048-5056.

Wang, T., Thornhill, S., \& De Castro, J. O. (2017). Entrepreneurial orientation, legitimation, and new venture performance. Strategic Entrepreneurship Journal, 11(4), 373-392.

Yang, M., \& Gabrielsson, P. (2017). Entrepreneurial marketing of international high-tech business-to-business new ventures: A decision-making process perspective. Industrial Marketing Management, 64, 147-160.

Yin, R. K. (2003). Case study research: Design and methods (third edition). London: Sage Publications.

Yin, R. K. (2009). Case study research: Design and methods (applied social research methods). London and Singapore: Sage.

Zimmerman, M. A., \& Zeitz, G. J. (2002). Beyond survival: Achieving new venture growth by building legitimacy. Academy of Management Review, 27(3), 414-431. 